\title{
The Effect of Dietary Counseling on Nutrient Intakes in Gastric Banding Surgery Patients
}

\author{
Meena Shah, Ph.D., Beverley Adams-Huet, M.S, Sneha Rao, M.D., Peter Snell, Ph.D., \\ Claudia Quittner, M.S., R.N., and Abhimanyu Garg, M.D. \\ Division of Nutrition and Metabolic Diseases (MS, SR, CQ, AG), Department of Clinical Sciences \\ (BAH), Department of Internal Medicine (MS, BAH, PS, AG), and Center for Human Nutrition \\ (MS, SR, CQ, AG), University of Texas Southwestern Medical Center at Dallas, Texas, and the \\ Department of Kinesiology (MS), Texas Christian University, Fort Worth, Texas.
}

\begin{abstract}
Background-There is some evidence that bariatric surgery patients who undergo the purely restrictive procedures, such as the gastric banding (GB) or vertical banded gastroplasty surgery, do not meet the dietary reference intakes for several nutrients. Whether dietary counseling improves micro- and macro-nutrient intakes was examined in GB surgery patients.
\end{abstract}

Methods-Twenty-three GB surgery patients received dietary and behavioral counseling for 12 weeks to limit energy intake and improve nutrient intakes. Food intake was assessed by 3 -d food record at baseline and 6 and 12 weeks. Post-intervention data were available in 21 patients.

Results-At baseline, more than 50\% of the subjects reported inadequate dietary intakes of 13 nutrients but over-consumption of sodium and percent energy from saturated and trans fatty acids. Mixed effects model for repeated measures revealed a significant reduction in energy $(\mathrm{p}=0.0007)$, absolute protein $(\mathrm{p}=0.04)$, cholesterol $(\mathrm{p}=0.045)$, and potassium $(\mathrm{p}=0.01)$ intake and an increase in vitamin $\mathrm{K}(\mathrm{p}=0.03)$ intake and percent energy from protein $(\mathrm{p}=0.005)$ over the 12 weeks. $\mathrm{McNemar}$ test showed a reduction in the proportion of subjects with an inadequate intake of vitamin $\mathrm{K}(\mathrm{p}=0.008)$ but an increase in the proportion of subjects with an inadequate intake of thiamin ( $\mathrm{p}=0.03)$ at 12 weeks. The proportion of subjects who did not meet the nutrient requirements for the remaining 27 nutrients was generally high and remained unchanged.

Conclusions-Dietary intervention improved the intake of some nutrients in GB surgery patients. However, most nutrient intake requirements remained unmet by many subjects. These results indicate that nutritional counseling beyond 12 weeks is warranted in GB surgery patients to improve their dietary nutrient intakes.

\section{Keywords}

gastric banding surgery; dietary intervention; nutrient intake

Corresponding Authors: Meena Shah, Ph.D., Clinical Associate Professor, Division of Nutrition and Metabolic Diseases, Center for Human Nutrition, UT Southwestern Medical Center, 5323 Harry Hines Blvd., Dallas, Texas 75390-8537,

meena.shah@utsouthwestern.edu and Professor, Department of Kinesiology, Fort Worth, Texas, m.shah@tcu.edu and Abhimanyu Garg, M.D., Professor and Chief, Division of Nutrition and Metabolic Diseases, UT Southwestern Medical Center, 5323 Harry Hines Blvd., Dallas, Texas 75390-8537. abhimanyu.garg@utsouthwestern.edu.

Conflict of Interest

The authors have no conflicts of interest to declare. 


\section{Introduction}

Gastric banding (GB) surgery is considered to be an effective treatment for severe obesity (defined as body mass index (BMI) of $\geq 40 \mathrm{~kg} / \mathrm{m}^{2}$ ) and the co-morbidities associated with this condition ${ }^{1-3}$. There is some evidence that bariatric surgery patients who undergo the purely restrictive procedures, such as the gastric banding (GB) or vertical banded gastroplasty (VBG) surgery, do not meet the dietary reference intakes for several nutrients. Colles and colleagues ${ }^{4}$ who followed GB surgery patients for 12 months post-operatively, reported a substantial decrease in protein intake and the mean protein intake was below the recommended reference value at the end of the study. The authors did not provide data on the micro-nutrient and some of the macro-nutrient intakes, however. More recently McGrice and Porter ${ }^{5}$ followed GB surgery patients for 12 months post-operatively and reported a high intake of total and saturated fat at 12 months. Many of their subjects did not meet the protein requirement at 12 months. Data on micro-nutrient intakes were not provided but the authors speculated that a low protein intake may co-exist with dietary zinc, iron, and $\mathrm{B}_{12}$ deficiency. Trostler and colleagues ${ }^{6}$ collected dietary data in patients who had undergone VBG surgery and reported that the dietary intake of many micro-nutrients decreased and was below the reference intakes at 12 months post-operatively. In all three studies, the patients had received varying amounts of standard dietary counseling as part of their routine care. The reduction in dietary protein and micro-nutrient intake following purely restrictive procedures may be due to reduced food intake, food intolerance, and non-compliance to nutritional recommendations $^{7-11}$.

It is not known whether dietary and behavioral counseling focused on meeting the nutrient requirements as well as restricting energy intake will lead to an improvement in the dietary macro- and micro-nutrient intakes in GB surgery patients. This is important to examine since poor nutrition is linked to a number of chronic conditions such as cardiovascular disease $^{12,13}$ and this relationship may not be modulated with vitamin and mineral

supplements ${ }^{14}$. In addition, according to one systematic review on nutrient intakes following GB surgery ${ }^{15}$, the lack of dietary intervention studies in this population preclude the development of evidence based dietary strategies that may help to optimize their health outcomes.

The aim of the present study was to examine the effect of dietary counseling on changes in nutrient intakes in GB surgery patients. We hypothesized that dietary counseling would lead to a decrease in energy intake and improvement in dietary macro- and micro-nutrient intakes in these patients.

\section{Materials and Methods}

\section{Subjects}

Twenty-three GB surgery patients underwent dietary counseling. The eligibility criteria included having undergone bariatric surgery at least 12 weeks earlier, having a BMI of 35 $\mathrm{kg} / \mathrm{m}^{2}$ or more, being $18-65 \mathrm{y}$ old, and being sedentary (exercising $<20 \mathrm{~min} /$ day over the past 12 weeks). Exclusion criteria included weighing $>180 \mathrm{~kg}$, having functional limitations that would preclude exercise, taking weight loss medications, presence of serious cardiovascular disease, uncontrolled hypertension, hematocrit $<30 \%$, chronic kidney disease, untreated thyroid disorders, severe pulmonary disease, or major neuro-psychiatric illnesses, pregnancy, lactation, or taking recreational drugs. All subjects signed the informed consent approved by the Institutional Review Board of UT Southwestern Medical Center. 


\section{Experimental Design}

This study involved a non-controlled design examining the effect of dietary and behavioral counseling over 12 weeks on macro- and micro-nutrient intakes in GB surgery patients. The data were obtained from a 12 weeks study on the feasibility and efficacy of exercise in bariatric surgery patients. The data on the feasibility and efficacy of the exercise program have been published elsewhere ${ }^{16}$. Subjects in both the exercise and control groups underwent the same dietary intervention to restrict energy intake and improve the dietary macro- and micro-nutrient intakes. The change in nutrient intakes over 12 weeks was not different between the exercise and control groups and the two groups were combined.

\section{Dietary Intervention}

The subjects received individual dietary counseling, in person and/or by telephone, every two weeks. Each session lasted approximately 30 minutes. The counseling was provided by an investigator with a doctorate in nutrition (MS).

All subjects were instructed to limit their energy intake to $1200-1500 \mathrm{kcal} / \mathrm{d}$ and to follow the dietary recommendations by the American Society for Metabolic and Bariatric Surgery (ASMBS) for GB surgery patients ${ }^{7,17}$ and the Dietary Guidelines for Americans ${ }^{18}$ as described below. To restrict their energy intake, the subjects were asked to limit food portion sizes, energy dense foods, energy containing beverages, and foods prepared using high-fat cooking methods. To enhance satiety, they were asked to take at least $20 \mathrm{~min}$ to eat the main meal, not drink during and 30 min before and after a meal, consume at least $60 \mathrm{~g}$ of protein per day, and include some fiber rich foods in meals. According to Raftopoulos et al. ${ }^{19}$, compliance with the protein requirement is associated with an improved percentage of lean body mass in bariatric surgery patients during weight loss. To meet the protein requirement, the subjects were instructed to consume fish, poultry without skin, lean meats, and egg whites, and to consume the protein rich foods before the carbohydrate or fat rich foods. The subjects were also instructed to include in their diet at least 5 servings of fruit and vegetables per day, especially green leafy and orange and deep yellow vegetables, peas and beans, a minimum of 2 servings of fatty fish such as Atlantic salmon, anchovies, sardines, rainbow trout, or tuna per week, and 2 liter (64 oz.) of water sipped in small amounts throughout the day. Other instructions included choosing whole-grains versus refined grains, low-fat versus higher fat dairy, and oils such as canola and olive oil, and limiting foods high in saturated fats, trans fatty acids, cholesterol, and sodium.

The patients were asked to take multivitamin-mineral supplements as recommended by the American Society for Metabolic and Bariatric Surgery ${ }^{7,20}$. This included calcium and vitamin D as well as multivitamin-mineral supplements.

\section{Behavioral Therapy}

The subjects received standard behavioral therapy including goal setting, self-monitoring, stimulus control, eating behavior, stress management, cognitive behavioral strategies, and problem solving and relapse prevention. The behavioral counseling was provided on an individual basis along with dietary counseling and by the same investigator (MS).

\section{Measurements}

Information on demographics and health history was collected at baseline. Data on dietary intake, supplement use, and blood nutrient levels were collected at baseline and 6 and 12 weeks. 


\section{Dietary and Nutrient Intake Assessment}

Dietary intake was evaluated by 3-d food record, a valid measure for assessing food intake $^{21}$. The subjects were instructed to keep a detailed record of their food and drink intake and the amounts consumed on two weekdays and one weekend day. They were asked to use kitchen scales and/or household measures such as cups and spoons and the serving size information provided on the processed food labels to assess portion sizes. They recorded their food intake on a 3-day food record booklet provided.

The 3-day food records were analyzed using the University of Minnesota Nutrition Data System for Research (NDSR) (version 5.0-3.5). The food records were analyzed by one of the investigator (SR) and a research assistant and were checked by another investigator (MS). The nutrient analysis software program includes over 18,000 foods including 7,000 brand name products. The ingredient choices and preparation methods provides more than 160,000 food variants.

The proportion of subjects who were at a risk for inadequate nutrient intakes was ascertained as recommended for groups by determining the percentage of subjects who had nutrients intakes below the Estimated Average Requirement (EAR $)^{22}$. EAR is a Dietary Reference Intake (DRI) ${ }^{23-29}$ and has been set by the Institute for Medicine (IOM) for vitamins A, C, D, and $\mathrm{E}$, thiamin, riboflavin, niacin, vitamin $\mathrm{B}_{6}$, folate, vitamin $\mathrm{B}_{12}$, calcium, copper, iron, magnesium, phosphorus, selenium, and zinc. For nutrients without EAR standards, the prevalence of inadequate/high intake was determined using other references including Adequate Intake (another DRI) for linoleic acid, alpha-linolenic acid, fiber, vitamin K, pantothenic acid, potassium, and sodium, the Dietary Guidelines for Americans for cholesterol and \% energy from saturated $\mathrm{fat}^{30}$, the American Heart Association guidelines for eicosapentaenoic acid (EPA) plus docosahexaenoic acid (DHA) and \% energy from trans $\mathrm{fat}^{31}$, and the American Society for Metabolic and Bariatric Surgery guideline for protein (at least $60 \mathrm{~g} / \mathrm{d})^{7,8}$.

Vitamin and mineral supplement use was determined by self-report. The data on supplement use was not included with the total dietary nutrient intakes since the goal of the study was to assess the effect of dietary counseling on dietary nutrient intakes.

\section{Serum Indicators of Nutritional Status}

Fasting serum iron, magnesium, phosphorus, potassium, calcium, total protein, albumin hemoglobin, and hematocrit levels were assessed by Quest Diagnostics (Irving, TX). The proportion of subjects who had deficient serum nutritional values was determined by comparing the serum levels for each of these variables with the respective reference ranges published by the U.S. National Library of Medicine and the National Institutes of Health ${ }^{32}$.

\section{Statistical Analyses and Power}

The effect of dietary counseling on energy and nutrients intakes was assessed by mixed effects model for repeated measures. The change in nutrient intake from baseline to 6 and 12 weeks was assessed by differences of least square means. The nutrient intakes are presented as medians and ranges. The change in the proportion of subjects who did not meet the nutrient intake requirements from baseline to 6 and 12 weeks was assessed using the McNemar test.

Mixed effects models for repeated measures were also used to examine the effect of ethnicity (non-Hispanic whites vs. others), education level (high school or less vs. some college or more), time since surgery ( $<1 \mathrm{y}$ vs. $\geq 1 \mathrm{y}$ ), presence or absence of type 2 diabetes, hypertension, or dyslipidemia, and whether or not the patient underwent banding 
adjustments during the study on energy intake. The results showed no interaction effect between time and any of the above variables. The trends in energy intake over time remained the same within the different categories of the above variables. Only unadjusted data are presented in the results.

Two subjects who did not provide nutrition data after baseline were excluded from the analyses. All analyses were carried out using SAS statistical software, version 9.2 (SAS Institute, Cary, NC).

Power analysis showed that a sample size of 17 subjects will have $90 \%$ power to detect a reduction in energy intake of $500 \mathrm{kcal}$ between baseline and 12 weeks with a standard deviation of $600 \mathrm{kcal}^{16}$. Based on this calculation, our sample size $(\mathrm{n}=21)$ had a $95 \%$ power to detect a $500 \mathrm{kcal}$ change in energy intake over 12 weeks.

\section{Results}

Subject descriptive characteristics are presented in Table 1. Average (mean \pm SD) age was $49.3 \pm 10.5 \mathrm{y}$. Ninety-one percent of the subjects were female and $57.1 \%$ were non-Hispanic Whites. The subjects would be classified as severely obese based on their mean BMI. The mean duration since surgery was $1.8 \pm 1.5 \mathrm{y}$. Prevalence of diabetes, hypertension, hypercholesterolemia, low levels of high density lipoprotein cholesterol, and hypertriglyceridemia was $4.8 \%, 57.1 \%, 52.4 \%, 38.1 \%$, and $23.8 \%$, respectively.

Six subjects underwent banding adjustments and they underwent the procedure only once during the study. Details on the band type and condition at the time of insertion are not available. No complications of surgery during the study were reported other than gastroesophageal reflux disease in 6 subjects at baseline and 4 subjects at 6 and 12 weeks and cholelithiasis in one subject at baseline. Body weight (mean \pm SD) was $108.6 \pm 16.5 \mathrm{~kg}$ at baseline, $107.1 \pm 16.3 \mathrm{~kg}$ at 6 weeks, and $104.5 \pm 14.4 \mathrm{~kg}$ at 12 weeks. Body weight was significantly $(\mathrm{p}<0.05)$ lower at 6 and 12 weeks compared to the baseline value.

The reported energy and dietary macro-nutrient intakes are presented in Table 2. Energy intake, percent energy from protein, absolute protein intake, and cholesterol intake changed significantly over 12 weeks. Energy and cholesterol intake decreased at $6(\mathrm{p}=0.0002$ and $\mathrm{p}=0.02$, respectively) and 12 ( $\mathrm{p}=0.03$ and $\mathrm{p}=0.04$, respectively) weeks compared to the respective baseline value. Percent energy from protein increased at 6 weeks $(\mathrm{p}=0.02)$ and 12 weeks $(\mathrm{p}=0.006)$ whereas absolute protein intake decreased at 6 weeks $(\mathrm{p}=0.03)$ compared to the respective baseline value. Percent energy from trans fatty acids was not significantly different over 12 weeks ( $\mathrm{p}=0.12$ ) but the value at 12 weeks was significantly lower $(\mathrm{p}=0.049)$ compared to the baseline value. Linoleic acid intake also did not change significantly over 12 weeks $(\mathrm{p}=0.06)$ but the intake at 6 weeks was significantly lower $(\mathrm{p}=0.02)$ compared to the baseline value. There was no significant change in the intake of percent energy from total fat and saturated fat, linolenic acid, EPA+DHA, and dietary fiber over 12 weeks.

The reported dietary micronutrient intakes are presented in Table 3. Over the 12 weeks, a significant change in micronutrient intake was only seen for vitamin $\mathrm{K}$ and potassium. The subjects reported consuming more vitamin $\mathrm{K}$ at 12 weeks $(\mathrm{p}=0.009)$ and less potassium at 6 weeks ( $\mathrm{p}=0.003)$ and 12 weeks $(\mathrm{p}=0.03)$ compared to the respective baseline value. In addition, the subjects reported consuming significantly less thiamin $(\mathrm{p}=0.03)$, riboflavin $(\mathrm{p}=0.03)$, selenium $(\mathrm{p}=0.047)$, and sodium $(\mathrm{p}=0.02)$ intake at 6 weeks compared to the respective baseline value. 
The proportion of subjects who did not meet the nutrient requirements is shown in Table 4 . At baseline, more than 50\% of the subjects reported inadequate dietary intakes of 13 nutrients but over-consumption of sodium and percent energy from saturated and trans fatty acids. There was a significant decrease in the proportion of subjects who did not meet the nutrient requirement for vitamin $\mathrm{K}$ at 12 weeks $(\mathrm{p}=0.008)$ compared to the baseline value. The proportion of subjects who had an inadequate intake of thiamin increased significantly at 12 weeks $(\mathrm{p}=0.03$ ) compared with the baseline value. There was no significant change in the proportion of subjects who did not meet the nutrient requirements for the remaining nutrients over 12 weeks.

Most subjects (71.4\%) reported taking vitamin and mineral supplements throughout the study. At least $86 \%$ of the subjects, however, did not meet the recommended supplement requirement for calcium with vitamin $\mathrm{D}$ at baseline, 6 weeks, or 12 weeks.

The proportion of subjects whose serum nutritional parameters were below the reference ranges is presented in Table 5. There was no change in the proportion of subjects who did not meet the serum nutritional reference ranges for any of the variables at either 6 or 12 weeks compared to baseline value. However, many subjects did not meet the reference ranges for hemoglobin and hematocrit at 12 weeks.

\section{Discussion}

Several beneficial changes in nutrient intakes were seen over 12 weeks. Reported energy intake decreased by more than $500 \mathrm{kcal}$ per day. Advising GB surgery patients to decrease energy intake is important since Sjostrom et al. ${ }^{33}$ have reported a progressive increase in daily energy intake from 1,500 kcal at 6 months to approximately 2,000 kcal at 4 and $10 \mathrm{y}$ following bariatric surgery (authors included patients with GB, Roux-en-Y gastric bypass, and VBG surgery) and this is associated with weight regain.

Percent energy from protein increased at follow-up. The absolute protein intake, however, decreased at 6 weeks and nearly $60 \%$ of the subjects were not meeting their absolute protein requirement of $60 \mathrm{~g}$ per day at either 6 or 12 weeks. Similar findings have been observed by three studies in which either GB or VBG surgery patients had received standard dietary counseling as part of their routine care. Colles and colleagues ${ }^{4}$ reported an increase in percent energy from protein but a decrease in the absolute protein intake at 12 months postoperatively in GB surgery patients and the absolute mean protein intake was below the recommended reference value. McGrice and Porter ${ }^{5}$ reported that many GB surgery patients did not meet the protein requirement at 12 months following surgery. Lastly Trostler et al ${ }^{34}$ observed a steep decline in percent energy intake from protein at 1 month followed by an increase to baseline values at 9 months post-operatively in patients who underwent VBG surgery. The percent energy from protein at 9 months was similar to the values seen at follow up in our study. The authors did not provide data on the absolute protein intake, however.

Cholesterol intake was reduced by about $25 \%$ at 6 and 12 weeks and most subjects did not exceed the reference intake for cholesterol at follow-up. Percent energy from trans fat was also reduced at 12 weeks. Most subjects, however, consumed more than the recommended amount of energy from trans fat at follow-up indicating a need to further emphasize the importance of limiting intake of trans fat. The reduction in cholesterol intake in GB surgery patients is corroborated by a study in non-bariatric surgery patients ${ }^{35}$ which reported a significant reduction in cholesterol intake following implementation of a cholesterollowering diet. No information on trans fatty acids was provided, however. Data on change in 
cholesterol and trans fat intake have not been reported in subjects who underwent either GB or VBG surgery.

Another beneficial contribution of the intervention was a $62 \%$ increase in vitamin $\mathrm{K}$ intake at 12 weeks and a decrease in the proportion of subjects who were not consuming enough vitamin $\mathrm{K}$ from $86 \%$ at baseline to $43 \%$ at 12 weeks. Another study in non-bariatric surgery patients, however, did not find any improvement in the proportion of subjects who had an inadequate intake of vitamin $\mathrm{K}$ following an 8 weeks intervention in which the subjects were asked to follow the Ornish diet, a diet rich in plant foods ${ }^{36}$. It is unclear why the Ornish diet did not lead to an increase in this vitamin since vitamin $\mathrm{K}$ is found in plant foods. In our study there was an emphasis on consuming green leafy vegetables which is a very rich source of vitamin $\mathrm{K}$. There is no comparison data on change in micro-nutrient intakes in GB surgery patients. Comparison data on micro-nutrient intakes in VBG surgery patients is not available for certain micro-nutrients such as vitamin K. Sodium intake tended to decline from baseline by about $30 \%$ but only significantly so at 6 weeks. Nevertheless a majority of the subjects consumed more than the adequate intake at follow-up suggesting the need for continued intervention in this area. These results are similar to a 3 y hypertension prevention study in which a large decrease in sodium intake was observed in subjects who were randomized to either an energy restriction or energy and sodium restriction group ${ }^{37}$.

There were several less desirable dietary changes during follow-up. Thiamin intake decreased by $15 \%$ at 6 weeks and more subjects were not meeting their thiamin intake requirement at 12 weeks compared to baseline. The subjects also decreased their intake of potassium throughout the study and linoleic acid, riboflavin and selenium at 6 weeks. There was no change in the proportion of subjects who did not meet the requirements for these nutrients, however. Nevertheless most of the subjects were not meeting their requirement for potassium and linoleic acid at follow-up. Trostler and colleagues ${ }^{6}$ also reported low intakes of thiamin, riboflavin (in men only), and selenium (in women only) at 12 months postoperatively in VBG patients. Data on potassium and linoleic acid were not reported, however.

The intervention did not change the proportion of subjects who did not meet the nutrient requirements for the remaining nutrients. Many subjects, however, did not meet the requirement for saturated fat, alpha-linolenic acid, EPA+DHA, dietary fiber, vitamin A, C, $\mathrm{D}$, and $\mathrm{E}$, niacin, vitamin $\mathrm{B}_{6}$, folate, vitamin $\mathrm{B}_{12}$, pantothenic acid, calcium, copper, iron, magnesium, phosphorus, and zinc at 6 and/or 12 weeks. Trostler and colleagues ${ }^{6}$ reported low intakes of vitamins $\mathrm{A}, \mathrm{D}, \mathrm{E}$ (women only), $\mathrm{B}_{12}$, and $\mathrm{B}_{6}$ (men only), niacin, folate, pantothenic acid, phosphorus (men only), magnesium, iron, calcium (men only), zinc, and copper at 12 months post-operatively in VBG surgery patients. Information on saturated fat, alpha-linolenic acid, EPA+DHA, and dietary fiber was not provided. McGrice and Porter ${ }^{38}$ noted a high intake of percent energy from saturated fat at 12 months post-operatively in GB surgery patients.

This study highlights a number of dietary issues that need to be addressed further when counseling GB surgery subjects. An emphasis on consuming more protein rich foods such as poultry without skin, fatty fish, lean meats, egg whites, low fat dairy, and legumes is warranted to meet the absolute protein requirement. This will also help to improve the intake of a number of minerals and some vitamins that were low in our subjects at follow-up. Fatty fish intake will also improve the intake of EPA and DHA. Emphasis on including more fruits, vegetables, whole grains, and nuts in the diet will further enhance the micro-nutrient content of the diet as well as increase the intake of dietary fiber. Limiting solid fats and partially hydrogenated fats to a greater extent than that seen in our study is necessary to prevent consuming too much energy from saturated and trans fats. The solid and partially 
hydrogenated fats can be replaced by vegetable oils such as canola and olive oils. These oils together will help to increase the omega-3, omega-6, and omega-9 content of the diet. Patients also need to further limit their intake of processed foods to reduce intake of sodium. All of the above emphases are recommended while controlling total energy intake. The current dietary guidelines by the ASMBS for GB surgery patients focus largely on lowering energy intake and maintaining an adequate protein intake with lesser or no emphasis on the other recommendations that we have made above. In addition, the protein intake goal of at least $60 \mathrm{~g}$ per day set by the ASMBS is not based on strong evidence and so it is uncertain what the optimal protein requirement is. More evidence based information on dietary issues in GB surgery patients may help to refine the dietary recommendations for this population.

Most subjects reported taking daily multi-vitamin and mineral supplements. This may counteract some of the dietary nutritional deficiencies observed during the study. Supplement use, however, would not address other shortcomings of a poor diet such as the phytochemical content of the diet or the link between a poor diet and chronic disease ${ }^{14}$. Analysis of blood nutrition status did not reveal any change in the proportion of subjects whose serum nutritional values were below the reference ranges. However, many subjects had lower than normal levels for hemoglobin and hematocrit at 12 weeks. Although less common than in Roux-en-Y gastric bypass surgery patients ${ }^{39}$, several studies have reported serum nutritional deficiencies related to thiamin, beta-carotene, vitamins E, selenium, and potassium in GB or VBG surgery patients ${ }^{6,40-42}$. Avsar et al. ${ }^{43}$ have also reported iron deficiency anemia in $32 \%$ of VBG patients following nutritional counseling. The inability of many of our subjects to meet the dietary and serum nutrient references, despite dietary counseling, further highlights the importance of providing ongoing dietary counseling, emphasizing the need to meet the recommended supplement requirements, and carefully monitoring serum nutritional status as recommended by the American Society for Metabolic $\&$ Bariatric Surgery ${ }^{7}, 20$.

Food intake in the present study was assessed by a 3-day food record, a validated measure for assessment of dietary intake ${ }^{21}$. Nevertheless, the method has some limitations including under-reporting and food selection bias ${ }^{21,44}$. Under-reporting has been shown to increase following weight loss interventions ${ }^{45}$. There is also the possibility of under-reporting due to social desirability bias. Under-reporting may contribute to some underestimation of nutrient intakes. To minimize the issues of food selection bias and under-reporting, the subjects were instructed to follow their usual food habits on the days that they recorded their food intake and any uncertain or incomplete information (e.g., lack of mention of snacks/drinks) in the food records was promptly addressed by questioning the subjects. The dietary data were also analyzed using an advanced nutrition analysis software program for research which probes for detailed data entry.

Other limitations include a pre-post design without a control group. This study is the first study, however, to examine whether a dietary intervention to restrict energy intake and enhance the quality of the diet improves macro- and micro-nutrient intakes in GB surgery patients and provides some evidence based data in this area. More rigorously designed studies are needed, nonetheless. The sample size is limited and larger controlled intervention studies need to be conducted to improve the generalizability of the results. Another limitation is subject heterogeneity. Adjusting for the duration since bariatric surgery, number of band adjustments, presence of certain health conditions, ethnicity/race, and education, however, did not affect the change in energy intake over time. In addition, having a more heterogeneous sample makes the results more generalizable. The counseling was offered by only one counselor with a track record in designing and implementing intervention studies. Results from this study may not be extrapolated to practitioners with different levels of experience in dietary intervention. Having one counselor in our study, however, ensured 
consistency of messages received by the subjects. It is possible that the impact of the dietary intervention was diluted by the fact that some of the subjects were also asked to exercise at the same time. We do not believe this to be the case, however, since there was no difference between the dietary versus the dietary and exercise intervention group in their nutrient intakes. The intervention was offered at an individual level. Whether a group based intervention to instruct and motivate the subjects leads to better adherence to the dietary guidelines remains to be evaluated. Lastly, the study was conducted for only 12 weeks without any further follow-up. A longer intervention and follow-up period is needed to determine if the intervention can be sustainable. It may be appropriate to begin the intervention before one year post-surgery, since Sjostrom et al. ${ }^{33}$ have shown that weight regain starts to occur around 1 year after GB surgery.

In conclusion, our study showed a reduction in energy, absolute protein, cholesterol, and potassium intake and an increase in vitamin $\mathrm{K}$ and percent energy from protein over 12 weeks in GB surgery subjects. At follow-up there was a decrease in the proportion of subjects who did not meet the requirement for vitamin $\mathrm{K}$ but an increase in the proportion who had an inadequate intake of thiamin. In addition most nutrients requirements, including the absolute protein requirement, remained unmet by many subjects. Further emphasis on consuming appropriate foods to meet the nutrient requirements and use of protein, vitamin, mineral, and omega-3 fat supplements is warranted in these patients.

\section{Acknowledgments}

We would like to acknowledge Drs. Savitha Shastry, Zahid Ahmad, and Vinaya Simha for providing clinical care to the patients during the study, Sarah Masood for assisting with data collection, Sheena Shah-Simpson for analyzing the dietary data, and Rosemary Son and Drs. David Provost, Nancy Puzziferri, and Nirmal S. Jayaseelan for helping to recruit the subjects.

Funding Source: The study was partly funded by NIH grants M01-RR00633, UL1-RR-024982, and UL1TR-000451, and by the Southwest Medical Foundation.

\section{References}

1. Buchwald H, Avidor Y, Braunwald E, et al. Bariatric surgery: a systematic review and metaanalysis. JAMA. 2004 Oct 13; 292(14):1724-1737. [PubMed: 15479938]

2. Dixon JB, O'Brien PE, Playfair J, et al. Adjustable gastric banding and conventional therapy for type 2 diabetes: a randomized controlled trial. JAMA. 2008 Jan 23; 299(3):316-323. [PubMed: 18212316]

3. O'Brien PE, Sawyer SM, Laurie C, et al. Laparoscopic adjustable gastric banding in severely obese adolescents: a randomized trial. JAMA. 2010 Feb 10; 303(6):519-526. [PubMed: 20145228]

4. Colles SL, Dixon JB, O'Brien PE. Hunger control and regular physical activity facilitate weight loss after laparoscopic adjustable gastric banding. Obes Surg. 2008 Jul; 18(7):833-840. [PubMed: 18408982]

5. McGrice MA, Porter JA. What are gastric banding patients eating one year post-surgery? Obes Surg. 2012; 22:1855-1858. [PubMed: 22923340]

6. Trostler N, Mann A, Zilberbush N, Charuzi II, Avinoach E. Nutrient Intake following Vertical Banded Gastroplasty or Gastric Bypass. Obes Surg. 1995 Nov; 5(4):403-410. [PubMed: 10733836]

7. Mechanick JI, Kushner RF, Sugerman HJ, et al. American Association of Clinical Endocrinologists, The Obesity Society, and American Society for Metabolic \& Bariatric Surgery medical guidelines for clinical practice for the perioperative nutritional, metabolic, and nonsurgical support of the bariatric surgery patient. Obesity (Silver Spring). 2009 Apr; 17(Suppl 1):S1-S70. [PubMed: 19319140]

8. Heber D, Greenway FL, Kaplan LM, Livingston E, Salvador J, Still C. Endocrine and nutritional management of the post-bariatric surgery patient: an Endocrine Society Clinical Practice Guideline. J Clin Endocrinol Metab. 2010 Nov; 95(11):4823-4843. [PubMed: 21051578] 
9. Schweiger C, Weiss R, Keidar A. Effect of different bariatric operations on food tolerance and quality of eating. Obes Surg. 2010; 20:1393-1399. [PubMed: 20680506]

10. Thomas JG, Bond DS, Ryder BA, et al. Ecological momentary assessment of recommended postoperative eating and activity behaviors. Surg Obes Relat Dis. 2011; 7:206-212. [PubMed: 21130703]

11. Overs SE, Freeman RA, Zarshenas N, Walton KL, Jorgensen JO. Food tolerance and gastrointestinal quality of life following three bariatric procedures: adjustable gastric banding, Roux-en-Y gastric bypass, and sleeve gastrectomy. Obes Surg. 2012; 22(4):536-543. [PubMed: 22170392]

12. Ford ES, Bergmann MM, Kroger J, Schienkiewitz A, Weikert C, Boeing H. Healthy living is the best revenge: findings from the European Prospective Investigation Into Cancer and NutritionPotsdam study. Arch Intern Med. 2009 Aug 10; 169(15):1355-1362. [PubMed: 19667296]

13. Flock MR, Kris-Etherton PM. Dietary Guidelines for Americans 2010: implications for cardiovascular disease. Curr Atheroscler Rep. 2011 Dec; 13(6):499-507. [PubMed: 21874316]

14. Kamangar F, Emadi A. Vitamin and mineral supplements: do we really need them? Int J Prev Med. 2012 Mar; 3(3):221-226. [PubMed: 22448315]

15. Dodsworth A, Warren-Forward H, Baines S. A systematic review of dietary intake after laparoscopic adjustable gastric banding. J Hum Nutr Diet. 2011 Aug; 24(4):327-341. [PubMed: 21414043]

16. Shah M, Snell PG, Rao S, et al. High-volume exercise program in obese bariatric surgery patients: a randomized, controlled trial. Obesity (Silver Spring). 2011 Sep; 19(9):1826-1834. [PubMed: 21681226]

17. Stocker DJ. Management of the bariatric surgery patient. Endocrinol Metab Clin North. Am. 2003 Jun; 32(2):437-457. [PubMed: 12800540]

18. United States Department of Agriculture. Dietary Guidelines for Americans. Available at: www.health.gov/dietaryguidelines/dga2005/document/.

19. Raftopoulos I, Bernstein B, O'Hara K, Ruby JA, Chhatrala R, Carty J. Protein intake compliance of morbidly obese patients undergoing bariatric surgery and its effect on weight loss and biochemical parameters. Surg Obes Relat Dis. 2011 Nov-Dec;7(6):733-742. [PubMed: 21925961]

20. Aills L, Blankenship J, Buffington C, Furtado M, Parrott J. ASMBS Allied Health Nutritional Guidelines for the Surgical Weight Loss Patient. Surg Obes Relat Dis. 2008 Sep-Oct;4(5 Suppl):S73-S108. [PubMed: 18490202]

21. Thompson FE, Byers T. Dietary assessment resource manual. J Nutr. 1994 Nov; 124(11 Suppl): 2245S-2317S. [PubMed: 7965210]

22. Murphy SP, Guenther PM, Kretsch MJ. Using the dietary reference intakes to assess intakes of groups: pitfalls to avoid. J Am Diet Assoc. 2006 Oct; 106(10):1550-1553. [PubMed: 17000187]

23. Institution of Medicine. Dietary Reference Intakes for Calcium, Phosphorus, Magnesium, Vitamin D, and Fluoride. Washington, DC: National Academies Press; 1997.

24. Institution of Medicine. Dietary Reference Intakes for Thiamin, Riboflavin, Niacin, Vitamin B6, Folate, Vitamin B12, Pantothenic Acid, Biotin, and Choline. Washington, DC: National Academies Press; 1998.

25. Institution of Medicine. Dietary Reference Intakes for Vitamin C, Vitamin E, Selenium, and Carotenoids. Washington, DC: National Academies Press; 2000.

26. Institution of Medicine. Dietary Reference Intakes for Vitamin A, Vitamin K, Arsenic, Boron, Chromium, Copper, Iodine, Iron, Manganese, Molybdenum, Nickel, Silicon, Vanadium, and Zinc. Washington, DC: National Academies Press; 2001.

27. Institution of Medicine. Dietary Reference Intakes for Energy, Carbohydrate, Fiber, Fat, Fatty acids, Cholesterol, Protein and Amino Acids. Washington, DC: National Academies Press; 2002 and 2005 .

28. Institution of Medicine. Dietary Reference Intakes for Water, Potassium, Sodium, Chloride, and Sulphate. Washington, DC: National Academies Press; 2005.

29. Institution of Medicine. Dietary Reference Intakes for Calcium and Vitamin D. Washington, DC: National Academies Press; 2011. 
30. U.S. Department of Agriculture and U.S. Department of Health and Human Services. Dietary Guidelines for Americans 2010. 7th Edition. Washington, DC: US Government Printing Office; 2010.

31. Lichtenstein AH, Appel LJ, Brands M, et al. Diet and lifestyle recommendations revision 2006: a scientific statement from the American Heart Association Nutrition Committee. Circulation. 2006 Jul 4; 114(1):82-96. [PubMed: 16785338]

32. U.S. National Library of Medicine and the National Institutes of Health. [Accessed June 2012] http://www.nlm.nih.gov/medlineplus/ency/article/003483.htm.

33. Sjostrom L, Lindroos AK, Peltonen M, et al. Lifestyle, diabetes, and cardiovascular risk factors 10 years after bariatric surgery. N Engl J Med. 2004 Dec 23; 351(26):2683-2693. [PubMed: 15616203]

34. Trostler N, Mann A, Zilberbush N, Avinoach E, Charuzi I. Weight loss and food intake 18 months following vertical banded gastroplasty or gastric bypass for severe obesity. Obes Surg. 1995; 5:39-51. [PubMed: 10733792]

35. Shah M, Kavanaugh A, Coyle Y, Adams-Huet B, Lipsky PE. Effect of a culturally sensitive cholesterol lowering diet program on lipid and lipoproteins, body weight, nutrient intakes, and quality of life in patients with systemic lupus erythematosus. J Rheumatol. 2002 Oct; 29(10): 2122-2128. [PubMed: 12375321]

36. Gardner CD, Kim S, Bersamin A, et al. Micronutrient quality of weight-loss diets that focus on macronutrients: results from the A TO Z study. Am J Clin Nutr. 2010 Aug; 92(2):304-312. [PubMed: 20573800]

37. Shah M, Jeffery RW, Laing B, Savre SG, Van Natta M, Strickland D. Hypertension Prevention Trial (HPT): food pattern changes resulting from intervention on sodium, potassium, and energy intake. Hypertension Prevention Trial Research Group. J Am Diet Assoc. 1990 Jan; 90(1):69-76. [PubMed: 2404050]

38. MccGrice MA, Porter JA. What are gastric banding patients eating one year post-surgery? Obes Surg. 2012; 22:1855-1858. [PubMed: 22923340]

39. Shah M, Simha V, Garg A. Review: long-term impact of bariatric surgery on body weight, comorbidities, and nutritional status. J Clin Endocrinol Metab. 2006 Nov; 91(11):4223-4231. [PubMed: 16954156]

40. Di Grande A, Giustolisi V, Tabita V, et al. Hypokalemic rhabdomyolysis in a patient with a laparoscopic adjustable gastric banding. Clin Ter. 2008 May-Jun;159(3):169-172. [PubMed: 18594746]

41. Coupaye M, Puchaux K, Bogard C, et al. Nutritional consequences of adjustable gastric banding and gastric bypass: a 1-year prospective study. Obes Surg. 2009 Jan; 19(1):56-65. [PubMed: 18542847]

42. Freeth A, Prajuabpansri P, Victory JM, Jenkins P. Assessment of selenium in Roux-en-Y gastric bypass and gastric banding surgery. Obes Surg. 2012; 22(11):1660-1665. [PubMed: 22714824]

43. Avsar FM, Ozel H, Topaloglu S, et al. Improvement of vertical banded gastroplasty by strict dietary management. Obes Surg. 2004 Feb; 14(2):265-270. [PubMed: 15018759]

44. Westerterp KR, Goris AH. Validity of the assessment of dietary intake: problems of misreporting. Curr Opin Clin Nutr Metab Care. 2002 Sep; 5(5):489-493. [PubMed: 12172471]

45. Johnson RK, Friedman AB, Harvey-Berino J, Gold BC, McKenzie D. Participation in a behavioral weight-loss program worsens the prevalence and severity of underreporting among obese and overweight women. J Am Diet Assoc. 2005 Dec; 105(12):1948-1951. [PubMed: 16321603] 
Table 1

Descriptive characteristics of the gastric banding surgery subjects $(n=21)$

\begin{tabular}{|l|c|}
\hline Variables & \\
\hline Age (y) & $49.3 \pm 10.5$ \\
\hline Female (\%) & 91 \\
\hline Race/Ethnicity (\%) & 57.1 \\
White, non-Hispanic & 33.3 \\
Black & 9.5 \\
Hispanics & $41.1 \pm 6.2$ \\
\hline Body Mass Index (kg/m²) & $1.8 \pm 1.5$ \\
\hline Duration from GB Surgery (y) & \\
\hline Health Conditions (\%) & 4.8 \\
Type 2 Diabetes & 57.1 \\
Hypertension & 38.1 \\
Hypercholesterolemia & 23.8 \\
Low levels of high-density lipoprotein cholesterol \\
Hypertriglyceridemia & \\
\hline
\end{tabular}

Values are means with standard deviations unless otherwise specified. 
Table 2

Energy and dietary macro-nutrient intake in gastric banding surgery subjects $(n=21)$

\begin{tabular}{|l|c|c|c|c|}
\hline Nutrient & Baseline & $\mathbf{6 ~ W e e k}$ & $\mathbf{1 2}$ Week & P Value $^{\mathbf{l}}$ \\
\hline Energy (kcal) & $1646(301-2617)$ & $1071(499-1684)^{2}$ & $1120(612-1833)^{4}$ & $\mathbf{0 . 0 0 0 7}$ \\
\hline Protein (\% energy) & $16.9(11.4-28.3)$ & $19.6(12.7-32.9)^{4}$ & $21.6(15.7-28.7)^{3}$ & $\mathbf{0 . 0 0 5}$ \\
\hline Protein (g) & $67.3(16.2-103.6)$ & $55.0(26.8-80.9)^{4}$ & $59.4(36.2-96.1)$ & $\mathbf{0 . 0 4}$ \\
\hline Total fat (\% energy) & $37.3(23.2-53.6)$ & $37.1(16.9-54.2)$ & $40.1(19.1-48.4)$ & 0.33 \\
\hline Saturated fat (\% energy) & $13.7(8.5-20.4)$ & $10.9(3.7-23.0)$ & $12.9(6.0-18.6)$ & 0.51 \\
\hline Trans fatty acids (\% energy) & $2.3(0.6-4.1)$ & $1.9(0.6-3.9)$ & $1.8(0.7-3.2)^{4}$ & 0.12 \\
\hline Linoleic acid (g) & $9.8(1.3-31.9)$ & $6.7(2.6-16.1)^{4}$ & $6.8(1.8-24.4)$ & 0.06 \\
\hline Linolenic acid (g) & $1.0(0.2-2.3)$ & $0.9(0.2-1.7)$ & $0.8(0.4-1.9)$ & 0.23 \\
\hline EPA+ DHA (mg) & $50.0(0-720.0)$ & $60.0(0-995.0)$ & $78.3(3.3-736.7)$ & 0.54 \\
\hline Cholesterol (mg) & $249.1(135.9-601.5)$ & $182.0(49.9-482.5)^{4}$ & $189.5(61.9-436.7)^{4}$ & $\mathbf{0 . 0 4 5}$ \\
\hline Fiber (g) & $9.5(2.5-16.9)$ & $9.6(5.3-23.7)$ & $10.3(6.4-19.1)$ & 0.17 \\
\hline
\end{tabular}

Values are shown as medians with minimum and maximum values in parenthesis.

${ }^{l}$ Change in intake over 12 weeks was assessed by repeated measures analysis.

${ }^{2} \mathrm{P}<0.001$ compared with the baseline value.

${ }^{3} \mathrm{P}<0.01$ compared with the baseline value.

${ }^{4} \mathrm{P}<0.05$ compared with the baseline value. 
Table 3

Dietary micro-nutrient intake in gastric banding surgery subjects $(\mathrm{n}=21)$

\begin{tabular}{|l|c|c|c|c|}
\hline Nutrient & Baseline & $\mathbf{6 ~ W e e k}$ & $\mathbf{1 2 ~ W e e k}$ & P Value $^{\mathbf{I}}$ \\
\hline Vitamin A $(\mu \mathrm{g})$ & $432.3 .1(129.5-4789.9)$ & $452.7(173.3-1740.8)$ & $529.3(218.1-804.6)$ & 0.68 \\
\hline Vitamin C $(\mathrm{mg})$ & $42.7(9.7-154.9)$ & $38.4(10.2-159.0)$ & $58.9(25.2-131.8)$ & 0.88 \\
\hline Vitamin D $(\mu \mathrm{g})$ & $2.7(0.6-22.2)$ & $1.9(0.9-14.2)$ & $2.3(1.1-7.8)$ & 0.37 \\
\hline Vitamin E (mg) & $4.8(1.1-10.9)$ & $4.2(1.9-16.4)$ & $4.7(1.5-11.5)$ & 0.71 \\
\hline Vitamin K $(\mu \mathrm{g})$ & $59.3(19.3-172.3)$ & $53.8(26.6-609.9)$ & $96.2(26.3-503.8)^{2}$ & $\mathbf{0 . 0 3}$ \\
\hline Thiamin $(\mathrm{mg})$ & $1.3(0.3-1.9)$ & $1.1(0.5-1.5)^{3}$ & $0.9(0.7-2.1)$ & 0.09 \\
\hline Riboflavin $(\mathrm{mg})$ & $1.4(0.5-4.4)$ & $1.2(0.5-1.7)^{3}$ & $1.2(0.6-2.3)$ & 0.09 \\
\hline Niacin $(\mathrm{mg})$ & $16.6(3.6-27.7)$ & $13.5(5.3-24.2)$ & $14.2(8.7-24.3)$ & 0.29 \\
\hline Vitamin $\mathrm{B}_{6}(\mathrm{mg})$ & $1.3(0.3-2.0)$ & $1.2(0.6-2.1)$ & $1.2(0.7-2.0)$ & 0.49 \\
\hline Folate $(\mu \mathrm{gg})$ & $323.9(75.2-665.6)$ & $294.4(125.0-852.9)$ & $343.5(206.6-634.0)$ & 0.72 \\
\hline Vitamin $\mathrm{B}_{12}(\mu \mathrm{g})$ & $3.8(0.7-32.2)$ & $2.9(1.3-7.8)$ & $3.2(1.2-6.6)$ & 0.37 \\
\hline Pantothenic acid $(\mathrm{mg})$ & $3.8(1.0-8.5)$ & $3.1(1.2-7.2)$ & $3.0(1.2-6.9)$ & 0.29 \\
\hline Calcium $(\mathrm{mg})$ & $622.2(157.6-2697.6)$ & $533.2(165.0-1373.8)$ & $585.3(348.5-1193.3)$ & 0.61 \\
\hline Copper $(\mu \mathrm{g})$ & $888.0(313.3-2353.3)$ & $746.7(426.7-1143.3)$ & $826.7(346.7-1700.0)$ & 0.12 \\
\hline Iron $(\mathrm{mg})$ & $9.6(3.0-16.9)$ & $9.2(3.9-20.2)$ & $9.5(7.0-21.5)$ & 0.19 \\
\hline Magnesium $(\mathrm{mg})$ & $211.1(56.3-300.6)$ & $166.6(115.3-352.6)$ & $196.3(96.4-500.7)$ & 0.33 \\
\hline Phosphorus $(\mathrm{mg})$ & $1001.9(301.5-2372.5)$ & $866.9(501.1-1203.6)$ & $901.8(500.5-1884.0)$ & 0.15 \\
\hline Selenium $(\mu \mathrm{g})$ & $87.0(20.5-140.6)$ & $66.6(30.7-155.2)^{3}$ & $69.5(45.8-139.1)$ & 0.13 \\
\hline Zinc $(\mathrm{mg})$ & $8.3(2.1-14.8)$ & $7.7(2.3-17.9)$ & $6.9(4.4-18.0)$ & 0.26 \\
\hline Potassium $(\mathrm{mg})$ & $2119.8(606.3-3486.6)$ & $1589.8(857.4-2475.3)^{2}$ & $1731.4(1077.7-2316.4)^{3}$ & $\mathbf{0 . 0 1}$ \\
\hline Sodium $(\mathrm{mg})$ & $3125.2(754.2-4287.4)$ & $2293.6(721.9-4480.3)^{3}$ & $2155.0(1226.5-4240.6)$ & 0.06 \\
\hline
\end{tabular}

Values are shown as medians with minimum and maximum values in parenthesis.

${ }^{1}$ Change in intake over 12 weeks was assessed by repeated measures analysis.

${ }^{2} \mathrm{P}<0.01$ compared with the baseline value.

${ }^{3} \mathrm{P}<0.05$ compared with the baseline value. 


\section{Table 4}

Proportion of gastric banding surgery subjects $(n=21)$ who did not meet the macro- and micro-nutrient intake requirements

\begin{tabular}{|c|c|c|c|}
\hline Nutrient & Baseline & 6 Week & 12 Week \\
\hline Protein & 38 & 58 & 57 \\
\hline Saturated fat (\% energy) & 90 & 68 & 79 \\
\hline Trans fat (\% energy) & 90 & 84 & 93 \\
\hline Linoleic acid & 67 & 89 & 79 \\
\hline Alpha-linolenic acid & 57 & 84 & 86 \\
\hline $\mathrm{EPA}+\mathrm{DHA}$ & 90 & 84 & 86 \\
\hline Dietary cholesterol & 33 & 16 & 21 \\
\hline Dietary fiber & 100 & 95 & 100 \\
\hline Vitamin A & 67 & 63 & 50 \\
\hline Vitamin C & 67 & 68 & 50 \\
\hline Vitamin D & 90 & 95 & 100 \\
\hline Vitamin E & 100 & 95 & 100 \\
\hline Vitamin $\mathrm{K}$ & 86 & 79 & $43^{l}$ \\
\hline Thiamin & 29 & 47 & $50^{2}$ \\
\hline Riboflavin & 19 & 16 & 29 \\
\hline Niacin & 19 & 26 & 29 \\
\hline Vitamin $\mathrm{B}_{6}$ & 33 & 53 & 43 \\
\hline Folate & 43 & 58 & 36 \\
\hline Vitamin $B_{12}$ & 14 & 16 & 29 \\
\hline Pantothenic Acid & 86 & 89 & 93 \\
\hline Calcium & 81 & 79 & 86 \\
\hline Copper & 33 & 32 & 43 \\
\hline Iron & 14 & 21 & 14 \\
\hline Magnesium & 90 & 84 & 86 \\
\hline Phosphorus & 14 & 16 & 14 \\
\hline Selenium & 14 & 11 & 0 \\
\hline Zinc & 33 & 47 & 50 \\
\hline Potassium & 100 & 100 & 100 \\
\hline Sodium & 90 & 79 & 86 \\
\hline
\end{tabular}

Change in proportion of subjects at risk of deficiency from baseline to 6 and 12 weeks was assessed by the McNemar test

${ }^{1} \mathrm{P}<0.01$ compared with the baseline value

${ }^{2} \mathrm{P}<0.05$ compared with the baseline value 
Table 5

Proportion of gastric banding surgery subjects $(n=21)$ who did not meet the serum nutritional references ranges

\begin{tabular}{|l|c|c|c|}
\hline Serum & Baseline & 6 Week & 12 Week \\
\hline Iron & 14 & 19 & 12 \\
\hline Magnesium & 0 & 0 & 0 \\
\hline Phosphorus & 0 & 0 & 0 \\
\hline Potassium & 5 & 0 & 12 \\
\hline Calcium & 0 & 0 & 0 \\
\hline Albumin & 10 & 0 & 6 \\
\hline Total Protein & 5 & 0 & 0 \\
\hline Hemoglobin & 35 & 10 & 53 \\
\hline Hematocrit & 20 & 0 & 41 \\
\hline
\end{tabular}

There was no change over 12 weeks in the proportion of subjects who did not meet the serum nutritional guidelines as assessed using the McNemar test. 